Kansas State University Libraries

New Prairie Press

\title{
Active Knowledge Sharing in Online Group Work
}

Bo Chang

Ball State University, changbo111@yahoo.com

Follow this and additional works at: https://newprairiepress.org/aerc

Part of the Curriculum and Instruction Commons, and the Online and Distance Education Commons (c) (i) (8)

This work is licensed under a Creative Commons Attribution-Noncommercial 4.0 License

\section{Recommended Citation}

Chang, Bo (2016). "Active Knowledge Sharing in Online Group Work," Adult Education Research Conference. https://newprairiepress.org/aerc/2016/papers/9

This Event is brought to you for free and open access by the Conferences at New Prairie Press. It has been accepted for inclusion in Adult Education Research Conference by an authorized administrator of New Prairie Press. For more information, please contact cads@k-state.edu. 


\title{
Active Knowledge Sharing in Online Group Work
}

\author{
Bo Chang \\ Ball State University
}

\begin{abstract}
The purpose of this paper is to explore how to support active knowledge sharing and creation in an online group work which both encourages collaboration and motivates individual effort.
\end{abstract}

Keywords: knowledge sharing; online group work, course design

\section{Introduction}

Knowledge sharing is crucial for learners to expand their learning resources and build a collaborative learning environment. Due to lack of physical communication, trust, and asynchronous communication, knowledge sharing in an online environment is challenging (Booth, 2012). Unlike face-to-face learning, online learning lacks facial expressions, as well as verbal and nonverbal cues, which makes it difficult to build trust in an online environment (Ridings et al., 2002; Young \& Tseng, 2008). Online group work as a commonly used strategy highly relies on shared written information and group interactions to create knowledge (Oliveira, Tinoca, \& Pereira, 2011). However, online group work can be a struggle, since it requires that everyone be on the same page, have commitment, and communicate on a regular basis. Many times, group members have too much to carry on their shoulders when they have to be responsible for themselves and also for others, which can be overwhelming, especially when there is more than one member who does not work well. Learners are often frustrated in online group work and resent the idea of online group work, resulting in learners' not sharing and creating new knowledge. It is a question of what strategies we can use to make everyone responsible for his/herself and reach a similar level of expectations for their group work. It is necessary to design a course in a way that allows learners to have a chance to collaborate and at the same time to maximize their individual potentials and responsibilities. It is important to find out how to support active knowledge sharing and creation in an online group work that both encourages collaboration and motivates individual effort, which is the purpose of this study.

\section{Literature Review}

Psychological variables, the organizational environment and knowledge management systems are some of the factors which impact knowledge sharing (Collins, Salgado, \& Cabrera, 2006). "Among the psychological variables, self-efficacy and openness to experience were the most salient variables" (Collins, Salgado, \& Cabrera, 2006, p.259). In terms of organizational variables, normative pressure, or the support from colleagues and supervisors impacts knowledge sharing. Other factors which may impact knowledge sharing include extrinsic rewards, availability of systems and quality of contents, autonomy, and the impact of social support.

Creating identities in online group learning can help members build trust and encourage them to share their experiences. Liu, Lin, Deng, Wu, and Tsai (2014) stated that sophisticated mechanisms are needed to increase mutual trust among members and further improve meaningful interactions and knowledge sharing among members. When members in a community are immersed in activities such as blogging, writing articles, and taking part in discussion forums, book club events and social bookmarking, they establish their firm identity 
and create "more fertile ground for knowledge sharing among members" (Booth, 2012, p.18). Educators can encourage members to provide detailed user profiles to increase the unique identities of the members in the community, and to promote opportunities for members to collaborate and share their expertise (Booth, 2012).

Simple knowledge exchange without meaningful interactions may not generate in-depth knowledge construction, however (Kao, Lin, \& Sun, 2008). Zygouris-Coe (2012) recommended some strategies which could motivate students to share and create knowledge actively, such as: (a) creating assignments which require students' interactions in small groups and across the entire class; (b) valuing students' engagement, synthesis and reflection; (c) making clear expectations of students' roles; (d) developing rubrics which address collaborative tasks and assigning grading values for collaboration; and (e) monitoring students' learning through progress reports and feedback. Lahtinen (2013) regarded that "Sharing different types and bases of knowledge and creating a common knowledge ground collaboratively were regarded as fruitful learning experiences" (p. 672). Developing infrastructures, creating a dynamic and fluid environment, and encouraging self-organized virtual networks enable learners to communicate effectively and promote knowledge sharing.

\section{Methodology}

In this study, two online courses (course 1 and course 2) operated through BlackBoard were selected. In both courses, the instructor designed the course activities and online learning environment in a way that aimed to promote active group work and knowledge sharing. 60 students enrolled in these two courses that were taught in two semesters.

Inspired by the works of Thomas, Clift, and Sugimoto (1996) and Poole (2000) in terms of how to categorize the contents of the messages, in these courses the following categorized information was provided to support students' learning: Content information (information which relates to course readings, and assignments), technical information (information about tools and techniques used in online courses. Such information was provided at the end of the syllabus), logistical information (information about handling the details which facilitate the main tasks to be done. Such information was provided through emails and announcements), and social information (information about personal life and news, social talk, etc. Such information was provided through the weekly Coffee and monthly summaries).

The structure of the courses included online discussions, individual assignments, group projects, and course reflections. For the online discussions, the instructor created small weekly online communities by posting several guiding questions each week. Each posted question was in one thread so that all the students who were interested in responding to a particular question would be in the same space. Students were required to respond to at least two questions and comment on at least two posts by other students. The instructor also gave students the freedom to generate their own questions and respond to the questions created by the students themselves.

The group project included four to five progressively designed assignments, in which each assignment served as the foundation for the next assignment. In each group assignment, the instructor divided the assignment into several major components; each assignment was designed in a way which required collaboration and individual accountability: Group members in each group were able to easily break up the tasks and complete one portion of the assignments independently. The value of the group collaboration and the duties and roles of each individual member were integrated into the grading rubrics. To motivate each group to share knowledge across groups, the instructor required the members of each group to post all of their assignments 
to their group blogs and comment on other groups' assignments. Each group's members were also required to summarize the process of their group work and share the tips, lessons, ideas, methods, and tools that they learned every month.

To provide triangulation and increase the validation, I collected multiple sources of data (Lincoln \& Guba,1985), including course reflections, course-related assignments, and students' accounts of their learning experience in these courses. The inductive content analysis method was used to analyze data, which includes open coding, creating categories and generalizing themes (Elo \& Kyngäs, 2008).

\section{Findings}

Several themes were generalized from the data, which include: (a) Transparent assignments shared in blogs stimulated knowledge sharing and interactive learning and were set up as a model or reference for students to follow; (b) transparent group work promoted acrossgroup learning which not only enabled students to learn knowledge of the topic they selected, but also expanded their knowledge in areas which were explored by other groups; (c) community and trust were created for knowledge sharing through video/audio introductions, as well as through weekly small discussion communities, and commenting on and following each group's work and monthly learning journeys; and (d) progressive and split assignments design with clearly defined components made course assignments manageable and promoted individual and collaborative learning. This design allowed group members to divide the tasks into individual pieces, which both promoted collaboration and satisfied the desire of individual members to work on part of the group assignments independently.

(Additional content has been omitted due to this article's page limit)

\section{Conclusions}

Transparent assignments shared in blogs stimulated knowledge sharing and interactive learning. Some students thought that this was a give-and-take process, and different perspectives were shared in this process.

Transparent assignments set up a model or reference for students to follow. Each group not only needs to share their assignments in group blog, but also comment on each other's work. By reading other students' work in blogs, students saw which areas could be improved and whether they were on the right track or not, or if they needed to do more. In this process, they were able to see each other's assignments and compare their assignments with those of others and see the differences between them, which provided a reference for them to improve their work.

Sharing their work in the public arena such as in blogs motivated students to treat their group work seriously since their assignments were not just for one specific course, but played a role as a public asset. Such external incentives motivated students to take full credit for their work and to fully understand the knowledge. They worked hard to make sure that they understood the contents, requirements and the application of the contents. Students also learned from the feedback from the instructor and students shared in group blogs. However, some students were opposed to their posting assignments in blogs due to their lack of technical skills. They thought that learning technology interferes with content learning.

Transparent group work promoted across-group learning. It benefited students' knowledge both in depth and in broadness. Following each group's work without having to perform it all individually, students not only learned knowledge in depth on the topic they selected, but also 
expanded their knowledge in other areas that were explored by other groups. Diverse ideas and topics were shared, and the scope of the knowledge was expanded since students could see the diverse ideas across the groups. Across group learning also happened when students read the tacit information in other groups' monthly summary. Sharing monthly summaries in blogs gave students an opportunity to share the tacit knowledge in blogs. Strategies and tips shared in the monthly summaries provided more dynamic, nuanced and tacit knowledge in terms of how students work as a group, and how they completed their group assignments, which helped other students improve their work too, after they read these summaries. Students also learned different ways of processing and presenting group work. Students could see how other groups approached their project differently from theirs, and were able to see the highlights of other groups' work. By visiting their peers' blogs, they learned about the issues that the instructor might gloss over or not cover. Knowledge from broader perspectives were shared, since their peers brought knowledge from different fields which their instructor lacked.

The progressive design of the assignments split the assignments into independent tasks so that students could easily divide the tasks into individual pieces. Most of the students liked the progressive design of the project assignments, since it makes a large assignment manageable and easier for each individual group member to complete one part of the assignment independently. It motivated group members' individual contributions by splitting the group work into portions and steps. Students liked that they were able to do only part of a large assignment individually. This method can help individual students achieve their learning goals step-by-step easily, and at the same time give students opportunities to work collaboratively with their group members. The progressive and split assignments design supported individual and collaborative learning. It accommodated students' different learning styles and satisfied students' desire to be able to work both individually and independently.

With the progressive design, the learning was sequential and thorough: Knowledge was revisited and reconfigured into the next task. Students needed to revisit their previous assignments, pull ideas from these assignments and integrate them into the final assignment. Students are able to connect what they have learned into a whole picture and tie old knowledge to the new and reinforce the knowledge they have learned. Students can digest a great deal of knowledge without having to perform it all individually and remain involved in the practical application of all group theories.

However, some students pointed out that the limitation of such a progressive assignment is that students individually worked on only one piece of the assignment and failed to synthesize the work as a group, which caused the group assignment to have a lack of creativity and cohesion. Some students thought that the different components of the assignment seemed disjointed from one another, as if the concepts were independent nuggets of information instead of interconnected building blocks of knowledge. It could also be a challenge for some students to configure the different parts of the projects.

Community and trust were built through video/audio introductions, weekly small discussion communities, and commenting on and following each other's group work and monthly learning journeys, which is beneficial for knowledge sharing. Requiring students to comment on each other's blog provides an opportunity for students to get connected. Through commenting, students had a chance to interact with other students, share their thoughts, and provide constructive feedback to each other. Through monthly summaries, tacit knowledge was shared and a space for emotional and social support was created. Students were able to document their learning journey and track other's work process. However, some students felt that all of 
these requirements, especially commenting on other's work, could become very tedious and laborious. The monthly summary may create a social space for learners to get connected and emotionally supported, but it is less relevant to content learning. In addition to their video introductions at the beginning of the course, some students suggested that students should provide more information about themselves, such as personal experience and group expectations to help other students get to know them better and to see if they are the right group members for each other.

\section{References}

Booth, S. E. (2012). Cultivating knowledge sharing and trust in online communities for educators. Journal of Educational Computing Research, 47(1), 1-31. doi:10.2190/EC.47.1.a

Collins, W. C., Salgado, J. F., \& Cabrera, Á. (2006). Determinants of individual engagement in knowledge sharing. The International Journal of Human Resource Management, 17(2), 245-264. doi:10.1080/09585190500404614

Elo, S., \& Kyngäs, H. (2008). The qualitative content analysis process. Journal of Advanced Nursing, 62(1), 107-115. doi:10.1111/j.1365-2648.2007.04569.

Kao, G.Y.M., Lin, S.S.J. , \& Sun, C.T. (2008). Beyond sharing: Engaging students in cooperative and competitive active learning. Educational Technology \& Society, 11 (3), 82-96.

Lahtinen, J. (2013). Local social knowledge management: A case study of social learning and knowledge sharing across organizational boundaries. Journal of Information Science, 39(5), 661-675. doi:10.1177/0165551513481431

Lincoln, Y.S., \& Guba, E.G. (1985). Naturalistic inquiry. Newbury Park, CA: Sage.

Liu, C., Lin, C., Deng, K., Wu, Y., \& Tsai, C. (2014). Online knowledge sharing experience with creative commons. Online Information Review, 38(5), 680-696. doi:10.1108/OIR-122013-0280

Oliveira, I., Tinoca, L., \& Pereira, A. (2011). Online group work patterns: How to promote a successful collaboration. Computers \& Education, 57(1), 1348-1357. doi:10.1016/j.compedu.2011.01.017

Poole, D. M. (2000). Student participation in a discussion-oriented online course: A case study. Journal of Research on Computing in Education, 33(2), 162-177.

Ridings, C. M., Gefen, D., \& Arinze, B. (2002) Some antecedents and effects of trust in virtual communities. Journal of Strategic Information Systems, 11(3\&4), 271-295. Retrieved from http://citeseerx.ist.psu.edu/viewdoc/download?doi=10.1.1.135.2663\&rep=rep1\&type=pdf

Thomas, L., Clift, R., \& Sugimoto, T. (1996). Telecommunication, student teaching, and methods instruction. An exploratory investigation. Journal of Teacher Education, 47(3), 165-174.

Young, M. L., \& Tseng, F. C. (2008). Interplay between physical and online settings for online interpersonal trust formation in knowledge-sharing practice. Cyber Psychology \& Behavior, 11(1), 55-64. doi: 10.1089/cpb.2007.0019

Zygouris-Coe, V. (2012, July). Collaborative learning in an online teacher education course: Lessons learned. In Linda Morris, \& Costas Tsolakidis (Eds.), Proceedings of the International Conference on Information Communication Technologies in Education (ICICTE)(pp.332-342), Rhodes, Greece. 